ENTREVISTA 


\title{
ENTREVISTA COM J OÃO EVANGELISTA DE ANDRADE FILHO: SOBRE ARTES VISUAIS E MUSEUS
}

\author{
Ana Lúcia Vilela \\ Doutoranda no PPGHST/UFSC \\ Fernando C. Boppré \\ Mestrando no PPGHST/UFSC
}

\author{
$\mathbf{U M}^{1}$ \\ Antes \\ eu era dois \\ ou mesmo três.
}

Às vezes quatro, cinco...

Com o apagar das luzes

eu fui ficando

cada vez mais

um.

Antes

tantas empreendi.

A giravolta,

Aquela que, em calma,

só a alma consegue percorrer,

e que dispensa asa,

hoje eu palmilho

dentro de casa.

\section{Antes}

a minha cama circulava em um rodízio...

O possuir era a essência da ventura.

Já me contento

com a aventura

não tão segura

de ser apenas.

De ser só um. 
João Evangelista de Andrade Filho é um dos nomes importantes no circuito das artes visuais em Santa Catarina. Atualmente diretor do Museu de Arte de Santa Catarina (MASC), já exerceu o mesmo cargo de 1958 a 1963, quando ainda se chamava Museu de Arte Moderna de Florianópolis (MAMF). É artista, professor, curador e crítico de arte. Nesta entrevista, concedida na biblioteca do Museu de Arte de Santa Catarina, João Evangelista falou sobre sua concepção de museus, o papel educativo destas instituições bem como sobre os critérios que devem balizar a formação dos acervos. Abordou, ainda, um tema bastante polêmico e pouco discutido no meio museológico: como proceder com o descarte de objetos no interior dos acervos?

ANA LÚCIA VILELA E FERNANDO C. BOPPRÉ: O senhor poderia falar um pouco da sua formação?

JOÃO EVANGELISTA DE ANDRADE FILHO: A minha formação foi primeiro obrigatória e depois libertatória. O meu pai me obrigou, por uma coação gentil e familiar, a fazer direito. É uma coação forte porque paterna. Eu fiz a faculdade de direito e entreguei a ele o diploma. Eu pude fazer, concomitantemente, a faculdade de letras neolatinas, chamava-se assim na época e se estudava francês, italiano, latim, etc. E depois eu fiz vestibular para cursar história e foi quando me ofereceram uma bolsa para estudar na França. Eu fui para lá e em vez da graduação eu fiz a pós-graduação em história da arte. Na França fui orientado por André Chastel que estava trabalhando sobre o renascimento italiano que era a especialidade dele. Isso convergiu com os meus interesses; o renascimento italiano já me interessava há algum tempo. Depois disso eu fui para à Itália e estava lá, sem um tostão, quando fui surpreendido pelo convite de Jorge Lacerda, então governador, para ingressar na Faculdade Catarinense de Filosofia para lecionar italiano também por causa da minha formação em letras neolatinas. Um currículo em letras e a propensão e a vontade de lecionar e estudar história. Eu acompanhei a criação da Universidade Federal de Santa Catarina, fui um dos fundadores. E fui professor, depois, do Departamento de História que, por sinal, cheguei a dirigir. Depois, fui indicado para lecionar história da arte no Instituto Central de Artes e também no Departamento de Arquitetura da Universidade de Brasília, com outros como o Darcy Ribeiro. Depois eu vim para cá dirigir o Museu de Arte Moderna de Florianópolis.

ANA LÚCIA VILELA E FERNANDO C. BOPPRÉ: Qual era a situação do acervo nos primeiros anos do Museu? 

museus

JOÃO EVANGELISTA DE ANDRADE FILHO: Ah, isso é uma história controversa. Precisaria definir o que é museu. Qual a sua função. Museu é uma questão palpitante e ao mesmo tempo polêmica, hoje. Mas felizmente é polêmica porque mostra que é uma questão importante. A situação do acervo do Museu não era boa. Existia um conjunto de obras, objetos até importantes, uns mais e outros menos, que não constituíam uma coleção. Na verdade era um conjunto que estava muito mal depositado num porão exposto às intempéries na antiga Casa Santa Catarina. Eu fui chamado para dar um jeito, justamente por causa dessa minha pós-graduação em história da arte e o meu perfil de jovem professor. Então eu consegui tirar os quadros do porão e expô-los, mesmo numa situação meio precária. Mas colocando o Museu para fora e lhe dando uma razão de existência. Minha preocupação era dar legitimidade ao Museu. A questão era: por que um museu em uma Florianópolis daquela época, em que a cultura estava passando por uma fase de desaceleração? A aceleração tinha sido marcada com o Grupo $\mathrm{Sul}^{2}$, a criação da revista e também com o Grupo de Artistas Plásticos de Florianópolis (GAPF) ${ }^{3}$. Daí o que nós fizemos? Só tinha uma funcionária, depois conseguimos uma secretária e eu era o diretor. Então eu fazia tudo. Ia colar cartazes na Praça XV de Novembro, entre outras coisas. Mas, sobretudo, eu percebi que um museu, de modo algum, podia ser apenas uma coleção de obras. Eventualmente o museu tem uma coleção de obras, um acervo que constitui a temática operativa do museu, por assim dizer. Essa coleção precisa ser captada, conservada, tem que ser estudada e divulgada. Essas funções são, por assim dizer, operacionais do museu. Mas não são a função cultural. Então eu pretendia ampliar, aquilo que eu supunha, à época, que fosse a função cultural, adaptada às necessidades da cidade. Então eu dava ênfase aos cursos e à discussão, que era até autocrítica, sobre o museu. Também dava muita ênfase às exposições didáticas para ensinar o que era impressionismo, o que era desenho. Eram discussões tópicas e didáticas e tinham como objetos coleções particulares minhas e reproduções dos livros de história da arte. Então tinha arte grega, arte egípcia, arte romana. A idéia era expor para a população a história da arte em geral. Eu convidava especialistas para darem cursos no Museu sobre essas etapas da história da arte e discutir. Então, tivemos do Egito ao Modernismo, cursos e discussões que eram concorridos. Se formos pensar nas proporções demográficas da cidade e, sobretudo, no nível educacional, o Museu era muito bem freqüentado. Porque também o pessoal da Faculdade Catarinense de Filosofia acorria bastante interessado. Então, para mim, o importante foi a criação de um público mais bem informado. A ênfase era mais em relação à criação de um público bem formado do que à quantidade de público. Não dava importância, naquela época, à formação quantitativa, a todo custo e a todo vapor, de um grande público. Isso era uma 
utopia, uma bobagem. Queríamos formar um público interessado que pudesse usufruir destas discussões e tivesse uma base para calcar as suas especulações particulares formando, claro, uma opinião e um olhar. O objetivo era formar uma maneira de se relacionar com o mundo através das obras expostas, originais ou não, e que na verdade estava na base de um novo olhar e um olhar local sobre a história da arte. Era um Museu de arte moderna. Então estávamos focando tudo no que seria o modernismo e dos seus valores.

ANA LÚCIA VILELA E FERNANDO C. BOPPRÉ: E como era a montagem das exposições?

JOÃo EVANGELISTA DE ANDRADE FILHO: Eu fazia tudo. Era só um funcionário. Inclusive naquela época não tinha nem máquina de escrever, então era tudo manuscrito. Era com aquela caligrafia cuidada que montava as referências artísticas de cada obra. O passe-partout era eu quem comprava com o meu dinheiro e colocava nas paredes que a gente pintava com o auxílio da Secretaria e movido pela boa vontade do Secretário de Cultura. Então ele nos dava força para comprar cortinas, mobiliário, etc. E eu achei que poderia reverter um pouquinho a condição e exercia a função de invasor imperialista ali dentro da Casa Santa Catarina. Então, invadi primeiro o Instituto Histórico-Geográfico de Santa Catarina, que não tinha função, ficava sempre vazio e tinha uma sala muito boa. Depois invadi a Academia Catarinense de Letras, porque também acontecia o mesmo com ela. Em seguida, eu coloquei no escritório o acervo, inclusive atrás das cortinas que mandamos fazer. Ali era um local mais adequado, considerando aquela época. Não tinha ar condicionado, condições e requisitos especiais necessários para a conservação das obras. Inclusive, só foi agora, recentemente, há uns quinze anos, mais ou menos, que temos as condições adequadas na reserva técnica para o acondicionamento e conservação das obras. Essa foi uma necessidade suprida pela Fundação Vitae através de um projeto feito na época em que o Harry Laus era o diretor. Mas, naquela época, invadimos e tomamos conta e a Casa Santa Catarina que ficou praticamente toda sendo um museu de arte. Daí estava na hora de eu sair. Então eu chamei o Carlos Humberto Corrêa, que era um aluno muito talentoso, que se destaca pelo interesse no campo das artes plásticas também e ele levou adiante o trabalho. Eu já tinha instalado a Escolinha de Artes dentro do museu. Eu não conseguia ver o museu sem arte-educação. $\mathrm{Na}$ época esse termo não existia, chamava escolinha de arte. Contudo, vamos voltar para trás: o Museu naquela época era uma coisa, hoje é outra e no futuro será uma outra ainda diferente. $\mathrm{O}$ museu tem funções que são históricas. Elas têm que se colocar de acordo com as necessidades mais globais de uma cultura ("cul- 

museus

tura" aqui numa acepção mais larga da palavra). E tem que fazer um esforço no sentido de colocar, não vou dizer o objeto, mas o assunto de que trata o museu de acordo com a cultura global do país. O museu de arte deve fazer com que haja um processo maior de capilaridade da cultura artística na cultura nacional como um todo. Com o museu de ciência, por exemplo, deve ser a mesma coisa, de antropologia e assim por diante. Mas o nosso assunto é arte. Então vamos dizer que competiria ao museu, eu pude fazer isso em Brasília, o segundo museu que eu dirigi, tentar furar uma certa barreira de opacidade que há na cultura geral do País em relação à cultura específica das artes visuais. Conseguimos. Lá tem um acervo maior. Usamos várias estratégias mas todas elas voltadas para que a arte fosse uma coisa da cidade, voltada para um olhar, o quanto mais possível novo e amplo, da cidade para o Brasil. Mas sempre voltado para aquilo que eu acho que é o verdadeiro objeto do museu, seja ele qual for, que é a educação. O museu não pode ter por objeto o patrimônio. Patrimônio é o instrumento através do qual o museu se exerce. Então o museu é um lugar onde se elaboram as condições para que seja criado, pelo público local de uma cidade ou de uma região, um olhar relacional para o objeto de arte, que possibilite esse olhar novo sobre a coisa, que diga algo além daquilo que havia antes. Então, em Brasília, eu presumo, sem modéstia também, ter acertado através de exposições chave que eram polêmicas e que abordavam coisas que não ficavam só no campo das artes. Eu procurava convidar antropólogos, especialista em filosofia da arte, em filosofia pura e simplesmente, em sociologia, etc. Através de discussões, de cursos, debates, entre intelectuais que estavam entre as melhores inteligências do momento, desde a Marilena Chauí, Gerd Bornheim, o [Sérgio Paulo] Rouanet (autor dessa lei que se tornou tão importante, e falha também em alguns sentidos, incompleta), e assim por diante. A nata da inteligência brasileira do momento e alguns artistas também como a Fayga Ostrower. Isso tudo para discutir como entender, como avaliar - não vou dizer julgar, que é uma palavra inadequada e pesada - a arte do momento. Acho que esse é o problema central para um museu de arte, mesmo que ele não seja um museu de arte contemporânea.

ANA LÚCIA VILELA E FERNANDO C. BOPPRÉ: A sua atuação, então, objetiva mais aprofundar as questões estéticas para um grupo menor do que atingir massiva e superficialmente uma população com grandes exposições. Qual sua opinião sobre as mega-exposições que, atualmente, ocupam diversos museus brasileiros e internacionais?

JOÃO EVANGELISTA DE ANDRADE FILHO: Como tudo mais, a verdade não tem domicílio fixo. Ela se esconde, ela aparece. Então tudo tem, até a pior 
coisa, tem um lado que pode ser aproveitado. Então essas grandes exposições podem ser interessantes desde que colaborem para ampliar a possibilidade do olhar. Em cidades que não têm acervos, que não têm oportunidade de mostrar efetivamente uma trajetória da arte nacional ou regional, enfim, que não têm objetos de valor e qualidade que possam suscitar essa visão, esse debate, essa discussão, aí sim essas grandes exposições podem ser válidas. Eu não quero falar só em gozo da obra de arte. Essa é, na verdade, uma expressão bonita. É interessante que as exposições tenham uma cenografia, que tenham uma montagem exuberante. Isso contribui, desde que não se desrespeite a natureza e a qualidade da obra de arte. Não me refiro à autonomia da obra de arte. Não é nada disso. Se a exposição trata de uma obra complexa, não se deve facilitar, fazer dela uma coisa muito atraente, apenas atraente, para que fique didaticamente assimilável. Neste caso se está traindo o autor e ao mesmo tempo o próprio público. Fica uma coisa barata e às vezes interessante para se colocar nas estatísticas oficiais mas de proveito duvidoso, porque está falseando a realidade histórica da obra apresentada. Então os grandes circuitos têm essa vantagem. Por exemplo, em São Paulo, que tem uma riqueza, claro que acantonada, restrita, a população toda não é rica, apenas uma parcela. Mesmo assim a maior parte desta população não terá acesso à arte chinesa. Então é bom que isso venha porque será proporcionado um contato com a estética chinesa. Isso tudo amplia os horizontes meditativos, não só de lazer. Nesse ponto acho que essas grandes exposições são válidas. Elas são muito caras e dependem de grandes patrocínios. Seria utópico pensar que essas grandes exposições pudessem ser feitas com poucos recursos. Elas não podem tomar o lugar da instituição local que está naquela cidade específica desprovida muitas vezes dessas oportunidades, de fazer e de propor ela própria as suas exposições e abordagens. Nesse ponto, acho que o quantitativo não deve imperar, ou seja, não se deve obter público a todo custo. Nesses casos, dessas exposições que visam primordialmente ou paralelamente, levar o nome da instituição patrocinadora, da empresa patrocinadora (para qualificar melhor) aos quatro cantos do país a sua marca, não penso que seja válido. A disseminação da marca é inevitável, mas ela não deve ocupar o lugar reflexivo e mesmo autocrítico que a própria instituição local deve assumir. Então acho que é preciso ter cuidado. Deve-se aceitar a exposição pronta quando ela convém ao projeto do próprio museu. Não se pode, num museu de província, expor apenas grandes nomes. É necessário divulgar grandes nomes, mas é também necessário expor o que é produzido localmente, às vezes de uma qualidade não tão brilhante ou significativa no panorama nacional, mas que possa até a vir a ser. É o caso de uma exposição que nós fizemos aqui no MASC que teve uma repercussão nacional e que ajudou a inserir o artista e sua obra e, conjuntamente, 

museus

a cultura e a mística local, no panorama nacional, que foi a exposição do Centenário de Martinho de Haro [ocorrida no ano de 2007]. A partir dela ele passou a ser reconhecido lá fora. Então o museu não pode abrir mão da discursividade. Ficar só na exposição não dá. É preciso fazer bons catálogos que representem bem a obra e, além disso, deve ser discutido do que a exposição trata. Eu acho que aí o museu começa a ter essa autonomia dialética que é importante para a criação desse tal olhar crítico. Essas exposições, se não ficarem apenas no número, elas são boas. Há uma convergência razoável de interesses. Mas se elas ferem as necessidades locais, a coisa já não fica tão virtuosa assim. No caso, a exposição da coleção Gilberto Chateubriand [realizada no MASC no ano de 2008] foi proposta por uma firma. Mas ela foi recebida aqui, porque nós achávamos que Santa Catarina, mesmo nesse momento, que já não é mais o de 1958, já evoluiu demais, temos uma universidade que é modelo no trabalho artístico que é o Centro de Artes (CEART) da UDESC. Mas mesmo assim muita gente daqui nunca tinha visto uma Tarsila do Amaral e não tinha tido oportunidade de discutir toda uma evolução da arte brasileira de uma coleção que não apenas configurava a ideologia do colecionador mas também, objetivamente, reflete um percurso, um itinerário da arte brasileira. Nesse ponto pode ser muito bom. Agora quando vem um pacote que reflete, pura e simplesmente, os interesses dos patrocinadores, aí é mais importante expor os valores locais que, às vezes não são tão brilhantes mas valores que são da população local.

ANA LÚCIA VILELA E FERNANDO C. BOPPRÉ: Como o senhor pensa a relação entre o público e o museu?

JOÃO EVANGELISTA DE ANDRADE FILHO: É preciso produzir um diálogo simbólico, quer dizer, sem esse relacionamento simbólico do museu com o público com seus próprios valores, que se faz ao longo de um trabalho, como é que se pode querer ser absorvido pelo próprio público? Então a exposição de um artista local, como é o caso do Meyer Filho, que assim que eu cheguei aqui nós fizemos e apoiamos uma exposição, por assim dizer, um pouco demagógica sobre a obra dele, mas valiosa porque realmente resumiu a obra e devolveu ao público uma imagem que já estava no seu universo afetivo. Esse e outros artistas como a Eli Heil que é uma artista realmente genial, diferente. Ela pode estar aqui ou na China, no Alasca; ela seria uma outsider, é um outro caso da história da arte. Mas esses artistas só vêm a tona para ter uma existência, por parte deles próprios em primeiro lugar, batalhando um lugar para expor, as vezes em praça pública, como era o caso do Meyer Filho, e quando a instituição consciente e responsável, o achou. Foi o que fizemos em 1958 quando assumimos o museu. Chamamos 
aquele grupo que estava para fundar o GAPF e eles ficaram ali a sombra do museu. Nós compramos o primeiro quadro do Meyer Filho, compramos o primeiro quadro do Rodrigo de Haro, compramos a primeira tapeçaria do [Pedro Paulo] Vecchietti, lançamos e levamos Vecchietti e Eli Heil para Brasília. Então é preciso que o museu os fizesse aparecer. Mas eles apareceram por esforço próprio e realmente fizeram com que as pessoas de fora confundissem a imagem de Santa Catarina com eles. A imagem da cidade de Florianópolis passou a ser uma imagem mediada pelo trabalho deles, o que é muito interessante como fato histórico.

ANA LÚCIA VILELA E FERNANDO C. BOPPRÉ: Em alguns de seus textos os senhor faz uma crítica da aproximação de alguns artistas tais como o Meyer Filho à uma estética surrealista. Como o senhor aborda esse problema?

JOÃO EVANGELISTA DE ANDRADE FILHO: O que o surrealismo faz? Trabalhar o inconsciente "conscientíssimamente". Eles fazem uma transposição das teorias de [André] Breton, das teorias da psicanálise para uma vivência pictórica que se resumia num tratamento automático da imagem. Dificilmente essa proposta poderia ter sido aplicada por nossos artistas porque é difícil pensar que exista uma história universal do surrealismo e muito menos um "nosso surrealismo". A única coisa que poderia estar relacionada à esta proposta seria a Eli Heil, mas ela já pertence à outra coisa, à pintura dos outsiders que é, de fato, outro assunto interessantíssimo. E ela tem seus colegas desde as décadas de 1960, 1970, na Europa. Na obra do Meyer Filho não há nenhum elemento que se possa dizer surrealista. Não é supra-real. Meyer é um artista da fantasia. O "phantastikós" não tem nada a ver com automação. Não é uma imagem puramente ditada pelo inconsciente. Todas as imagens de certo modo o são, mas aí é uma questão de grau. A pintura, mediante tudo isso, já interfere num valor afetivo, de tal modo que, no caso deles, apela-se para o folclore, para o rito popular, etc, ou seja, são muitas fontes que não estão no inconsciente. Há também outras fontes, como a dos quadrinhos, imagens que estão no cotidiano e fazem parte do imaginário ocidental. Então eles se apropriam disso, fazem uma arte extremamente original, bem elaborada do ponto de vista estético, da construção da imagem e daí não são surrealistas. Temos que lembrar que o Surrealismo é um programa.

ANA LÚCIA VILELA E FERNANDO C. BOPPRÉ: Como o senhor vê a obra de Franklin Cascaes, já que ele tinha um propósito mais documental?

JOÃO EVANGELISTA DE ANDRADE FILHO: O Cascaes tem uma linguagem bem original, bem própria que se aproxima ao trabalho da rendeira. Aquela 

museus

minúcia repetitiva e criadora de uma tecedura intimista da forma. Ele cria teias de formas. Isso tem sim um valor formal; não vamos dizer que seja surpreendente, mas é sim, muito interessante. Mas ele também está fora de um mundo surreal, fora do inconsciente. Ele vai procurar no inconsciente coletivo manifestado através de fontes populares, narrações que ele colheu, etc. permeados de um trabalho de antropologia, ele vai se apropriar dessas fontes e reelaborar de acordo com a avaliação artística dele. Não tem nada a ver com o Surrealismo. Mas acho muito interessante o trabalho dele porque também coloca, junto com Meyer Filho e Vecchietti, uma forma estilisticamente tão consistente e atuante. Eles foram criando um país fantástico, um espaço local, que justifica muito bem o título que Adalice [Maria do Araújo] deu ao trabalho deles, "Magia e Mito". Tudo bem, mas magia e mito, repetidos, interpretados e reinterpretados. Acho Cascaes um artista bem importante, embora ache o Meyer mais talentoso, mais conseqüente com uma criação, mas o Cascaes é igualmente importante. Acho muito interessante o título que a professora Rosangela Cherem deu ao Meyer, um "modernista saído da lira", porque é justamente isso, o lírico, fantástico; ele é o encantador.

ANA LÚCIA VILELA E FERNANDO C. BOPPRÉ: Quais são os critérios que o senhor acha pertinentes e adequados para a escolha, tanto das exposições, quanto do acervo do museu?

JOÃO EVANGELISTA DE ANDRADE FILHO: Depende do que o museu se propõe a fazer. Se for um museu regional, deverá escolher entre os valores regionais, assim como se for um museu de arte brasileira já terá um escopo maior. Se for um museu de arte contemporânea, já será diferente. O MASC é um museu de arte. Não abrigaria um vaso ou uma cerâmica utilitários, mesmo que valiosos, como no Museu de Estocolmo, por exemplo, onde a coisa mais bonita, a meu ver, é um armário com vidros art noveau. Como o MoMa de Nova York, que colocou máquina Olivetti como obras de arte, como exemplares do engenho artístico humano. Mas isto não se aplica aqui no MASC porque não é um museu de artes decorativas ou de artes industriais. Ele é um museu de arte. Então qual o critério? O critério deve ser a importância que determinada linha de produção teve sobre essa cidade na época que nós queremos considerar. Se Florianópolis ou o Estado de Santa Catarina foi colonizado por alemães, italianos, açoreanos, etc, então há resíduos importantes, para a construção do objeto de arte, que devem aparecer no acervo. Ou seja, devem ser objetos que fazem parte desse mundo que se quer discutir no museu, objetos de arte que criaram uma determinada cultura artística. Eu não acho que a manutenção do acervo seja a função principal do museu. Pode haver até museu com acervo provisório. Mas aqui essa função é importante. Então vamos 
coligir o quê? Coletar o quê? Aquilo que na nossa época se considere importante para a produção e o debate sobre arte. Então isso pode mudar daqui há setenta anos. O que não pode é absorver loucamente, por uma falta de critério absoluto, tudo o que se produz. Então eu acho que ainda vigora e é uma coisa polêmica e perigosa de se falar, mas o que tem que vigorar é a qualidade. Por isso que tem que se tocar, e não vai ser na conversa de hoje nem em muitos debates que se vai resolver isso, na possibilidade do descarte. Nós temos nas bibliotecas, toda um política de descarte. É uma coisa lógica e que tem que ser feita. E não pode descartar e dar para uma instituição mais desprovida, mais pobre. Isso seria ridículo, seria uma ofensa para a instituição que iria receber. Tem que ser incinerado, aquela produção tem que ser extinta.

ANA LÚCIA VILELA E FERNANDO C. BOPPRÉ: Como seria esse processo?

JOÃO EVANGELISTA DE ANDRADE FILHO: Eu não sei. Não sou museólogo, sou um diretor de museu que está, há muito tempo, tentado dar ao museu, aquilo que eu acho ele tem que ter: a possibilidade de relacionar objetos do mundo com um povo. Eu acho que para o descarte temos que recorrer ao museólogo, ao museógrafo, ao conservador; mas também tem que recorrer ao filósofo, ao químico, ao físico, ao antropólogo, etc, para evitar que os critérios fiquem uma coisa meio abstrata. É preciso agir transdisciplinarmente. Para o descarte é necessário que haja uma comissão de alto nível. O que seria isso? Uma comissão heterogênea de pessoas que, durante um certo tempo, demonstraram estar ligadas ao universo da produção artística, crítica, etc, para poder justificar o descarte. Porque de fato é fácil, para o conhecedor, ver a qualidade de uma obra. Mas justificar não é fácil. É preciso ter certeza, produzida pelo consenso, de que aquele objeto é deficiente em relação ao conjunto. Não é preciso conservar tudo para que se produza um caldo cultural que vá depois fazer parte da cultura geral do País. Acho então que tem muita coisa a ser descartada que não contribui. Toda a arte que é repetitiva, por exemplo, não tem porque conservar. Uma arte apenas ilustrativa não tem razão de estar num museu. Talvez uma obra que não seja tão importante e conste de um acervo pode construir o renome e produzir uma fortuna crítica de certos artistas que são super valorizados e as gerações repetem isso e acabam formando um acervo irreal e não um acervo atuante. Isso não tem sentido. Claro que essa idéia do descarte tem implicações. Requer um subsídio jurídico, porque se não o pobre do diretor do museu que for enfrentar uma coisa dessas será levado ao tribunal. Acho muito importante discutir isso, que a sociedade discutisse isso também. 
Entrevista com João Evagelista de Andrade Filho: sobre artes visuais e

Recebido em 15 de julho de 2008

\section{NOTAS}

I EVANGELISTA, João. Outros poemas \& treze números. Florianópolis: Agnus, 2000.

2 C Círculo de Arte Moderna que passaria a ser conhecido como Grupo Sul pode ser definido, resumidamente, como uma rede de artistas e intelectuais que se reuniram sob o "credo comum" da discussão e produção da arte moderna em Florianópolis, lançando assim novos valores. O principal veículo do grupo seria a Revista Sul, publicada de 1948 a 1957, num total de trinta números.

${ }^{3}$ O primeiro salão do Grupo de Artistas Plásticos de Florianópolis ocorreu em 1958. Como antecedente, contudo, a exposição de Hassis e Meyer Filho no Instituto Brasil-Estados Unidos (IBEU). Durante a exposição, conheceriam o tapeceiro Pedro Paulo Vecchietti e formariam o núcleo que coordenaria as primeiras investidas do Grupo. Além dos três artistas, juntar-se-iam Tércio da Gama, Hugo Mund Júnior, Aldo Nunes, Thales Brognoli, Dimas Rosa e Rodrigo de Haro. O GAPF é considerado, junto a Martinho de Haro, como o precursor do modernismo nas artes plásticas em Santa Catarina. 